\title{
Human cardiac potassium channel DNA polymorphism modulates access to drug- binding site and causes drug resistance
}

\author{
Benoit Drolet, ${ }^{1}$ Chantale Simard, ${ }^{1}$ Laura Mizoue, ${ }^{2}$ and Dan M. Roden' \\ ${ }^{1}$ Division of Clinical Pharmacology, Departments of Medicine and Pharmacology, ${ }^{2}$ Department of Biochemistry and the \\ Vanderbilt Center for Structural Biology, Vanderbilt University School of Medicine, Nashville, Tennessee, USA.
}

\begin{abstract}
Expression of voltage-gated $\mathrm{K}^{+}$channel, shaker-related subfamily, member 5 (KCNA5) underlies the human atrial ultra-rapid delayed rectifier $\mathrm{K}^{+}$current $\left(\mathrm{I}_{\mathrm{Kur}}\right)$. The $K C N A 5$ polymorphism resulting in $\mathrm{P532} \mathrm{L}$ in the $\mathrm{C}$ terminus generates $I_{K u r}$ that is indistinguishable from wild type at baseline but strikingly resistant to drug block. In the present study, truncating the $\mathrm{C}$ terminus of KCNA5 generated a channel with wild-type drug sensitivity, which indicated that P532 is not a drug-binding site. Secondary structure prediction algorithms identified a probable $\alpha$-helix in P532L that is absent in wild-type channels. We therefore assessed drug sensitivity of $I_{K u r}$ generated in vitro in $\mathrm{CHO}$ and HEK cells by channels predicted to exhibit or lack this C-terminal $\alpha$-helix. All constructs displayed near-identical $\mathrm{I}_{\mathrm{Kur}}$ in the absence of drug challenge. However, those predicted to lack the C-terminal $\alpha$-helix generated quinidine-sensitive currents $(43-51 \%$ block by $10 \mu \mathrm{M}$ quinidine), while the currents generated by those constructs predicted to generate a C-terminal $\alpha$-helix were inhibited less than $12 \%$. Circular dichroism spectroscopy revealed an $\alpha$-helical signature with peptides derived from drug-resistant channels and no organized structure in those associated with wild-type drug sensitivity. In conclusion, we found that this secondary structure in the KCNA5 C terminus, absent in wild-type channels but generated by a naturally occurring DNA polymorphism, does not alter baseline currents but renders the channel drug resistant. Our data support a model in which this structure impairs access of the drug to a pore-binding site.
\end{abstract}

\section{Introduction}

Expression of voltage-gated $\mathrm{K}^{+}$channel, shaker-related subfamily, member 5 (KCNA5) generates a potassium current with the characteristics of the ultra-rapid delayed rectifier $\mathrm{K}^{+}$current $\left(\mathrm{I}_{\mathrm{Kur}}\right)$, an important component of the electrophysiology of the human atrium (1-3). While the commonest arrhythmia currently treated with antiarrhythmic drugs is atrial fibrillation, affecting up to 5,000,000 Americans, available drugs often cause side effects and in particular the occasional generation of unwanted ventricular arrhythmias $(4,5)$. Because KCNA5 expression in human heart is confined to the atrium and $\mathrm{I}_{\mathrm{Kur}}$ is recorded in atrial but not ventricular cells, this gene product has become an attractive target for development of drugs to treat atrial fibrillation $(6,7)$.

We have recently screened the KCNA5 gene for polymorphisms in a panel of 180 ethnically identified, but otherwise anonymized, individuals (8). A nonsynonymous coding region single nucleotide polymorphism (cSNP), resulting in P532L in the C terminus of the channel, was identified in $1.1 \%$ of African Americans. Although current generated by a P532L KCNA5 construct was nearly identical to wild-type $\mathrm{I}_{\mathrm{Kur}}$, the channel was strikingly less sensitive to block by the antiarrhythmics quinidine and propafenone: the $\mathrm{IC}_{50}$ for current through wild-type channels was $8.4 \mu \mathrm{M}$, while that for P532L was $133 \mu \mathrm{M}(8)$. This result was entirely unexpected, as a drug-bind-

Nonstandard abbreviations used: CD, circular dichroism; $\Delta \mathrm{C}$-term ${ }_{527}$, truncation of the $\mathrm{C}$ terminus distal to position 527 ; $\delta$, electrical distance; $\mathrm{HEK}$, human embryonic kidney; $\mathrm{I}_{\mathrm{Kur}}$, ultra-rapid delayed rectifier $\mathrm{K}^{+}$current; KCNA5, voltage-gated $\mathrm{K}^{+}$channel, shaker-related subfamily, member 5; $\mathrm{K}_{\mathrm{v}} \beta$, accessory $\beta$ subunit of voltage-gated $\mathrm{K}^{+}$channel.

Conflict of interest: The authors have declared that no conflict of interest exists.

Citation for this article: J. Clin. Invest. 115:2209-2213 (2005).

doi:10.1172/JCI23741. ing site has previously been identified in the S6 region of this channel (9), as it has in other voltage-gated ion channels (10-12).

\section{Results}

In our initial report (8), we showed that wild-type and P532L channels displayed near-identical activation and deactivation characteristics but that $10 \mu \mathrm{M}$ quinidine blocked wild-type current by $49.6 \% \pm 7.5 \%$ and P532L current by $7.3 \% \pm 2.1 \%$.

These data were obtained in transfected $\mathrm{CHO}$ cells studied at room temperature. Accordingly, we have conducted further experiments to demonstrate that these differences are not confined to a narrow set of specific experimental conditions. When wild-type and $\mathrm{P} 532 \mathrm{~L}$ channels were studied at $37^{\circ} \mathrm{C}$ (Figure 1, A and B) in $\mathrm{CHO}$ cells, the same result was obtained: baseline currents were no different, but $10 \mu \mathrm{M}$ quinidine resulted in 50\% block of wild-type current and less than $10 \%$ block of P532L current. We also conducted the same experiment in human embryonic kidney (HEK) cells. Figure 1, C and D, shows that wild-type and P532L currents displayed very similar characteristics at baseline, but that, again, P532L current was much less sensitive to drug. Table 1 presents summary data: at baseline, there was no significant difference between wildtype and P532L current in amplitudes, the voltage dependence of activation, or the activation time constant and only a minor difference in the fast time constant for deactivation. However, while $10 \mu \mathrm{M}$ quinidine blocked wild-type current by $50.4 \% \pm 4.4 \%$, P532L current was suppressed by only $8.0 \% \pm 2.2 \%$.

P532L is not a cryptic drug-binding site

One possible mechanism underlying resistance to drug block by $\mathrm{P} 532 \mathrm{~L}$ is direct participation of the proline or adjacent residues in drug binding. Two lines of evidence strongly argue against this idea. 
A

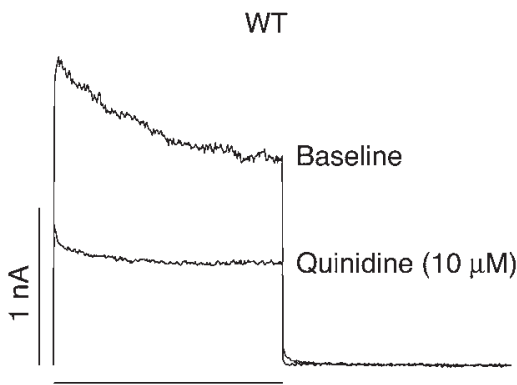

$250 \mathrm{~ms}$

C

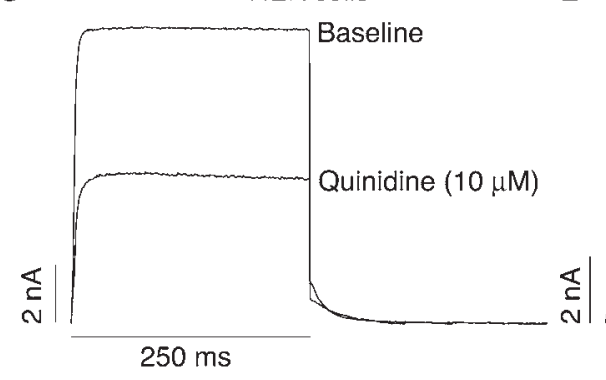

B

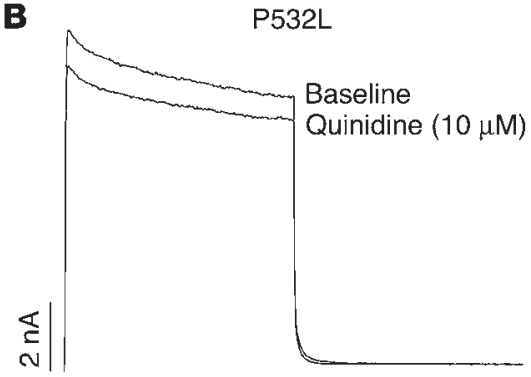

P532L

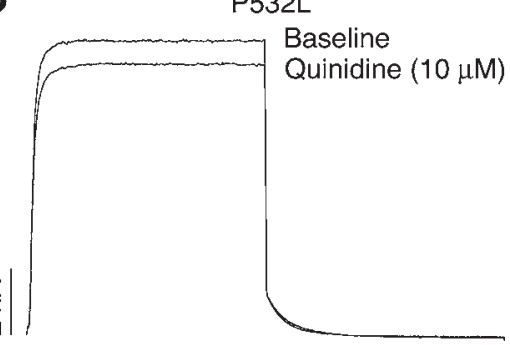

Figure 1

Electrophysiology and drug sensitivity of wild type (left panels) and P532L (right panels). (A) Wild-type activating current in $\mathrm{CHO}$ cells at +50 $\mathrm{mV}$ and tail current at $-30 \mathrm{mV}$ at baseline and after a 20-minute exposure to quinidine $10 \mu \mathrm{M}$ at $37^{\circ} \mathrm{C}$. (B) P532L studied under the same conditions as described for A. (C) Wild-type activating current in HEK cells at $+50 \mathrm{mV}$ and tail current at $-30 \mathrm{mV}$ at baseline and after a 20-minute exposure to quinidine $10 \mu \mathrm{M}$ at room temperature. (D) P532L studied under the same conditions as described for $\mathbf{C}$.
First, the electrical distance $(\delta)$ for the drug-binding site in wild-type and P532L channels was nearly identical (wild-type, $0.22 \pm 0.01$ versus P532L, $0.23 \pm 0.02 ; P=0.81$; Figure 2 ), which indicates that the site at which drug blocks the channel is located at a similar "depth" within the pore for the 2 channels, approximately $22 \%$ within the electric field, which is similar to previously reported values $(13,14)$. Second, we determined drug sensitivity of a construct in which the entire $\mathrm{C}$ terminus distal to position 527 was truncated $(\Delta \mathrm{C}$-term 527$)$. As shown in Figure $3 \mathrm{~A}, \Delta \mathrm{C}$-term ${ }_{527} \mathrm{KCNA5}$ displayed wild-type activation, deactivation, and drug sensitivity. Therefore, the proline at position 532 (absent in $\Delta$ C-term ${ }_{527}$ ) is not required for drug block of the channel.

\section{A predicted structural feature in the $C$ terminus}

In silico analysis of the $\mathrm{C}$ terminus suggested that substitution of any amino acid except glycine at position 532 would generate an $\alpha$-helix, as would deletion of the proline at this position ( $\Delta \mathrm{P} 532)$. Drug block at a series of point mutations at this position in addition to circular dichroism (CD) spectroscopy were used to test the hypothesis that generation of an $\alpha$-helix in this region modulates drug binding and channel blockade.

Drug block in P532 point mutations. First, current inhibition by quinidine was assessed in CHO cells in a series of P532 mutant channels. Substitution of alanine, glutamate, methionine, or ser- ine or deletion of the proline at position $532(\Delta \mathrm{P} 532)$ were predicted to generate an $\alpha$-helix in this region, whereas P532G was not. Table 2 shows that in the absence of drug, all 7 constructs tested (including $\Delta \mathrm{C}$-term ${ }_{527}$ ) exhibited similar in vitro properties, including current magnitude, the voltage at which half maximal current was activated, and time constants for activation, with minor differences in the time constants for deactivation; these are very similar to the values we previously reported for wild-type and P532L current (8). The effects of quinidine were determined at a concentration of $10 \mu \mathrm{M}$, which blocked wild-type current by $50 \%$. The 5 constructs predicted to generate an $\alpha$-helix in this region behaved just as P532L had: there was minimal $(<12 \%)$ current inhibition. Representative data for 3 of these are shown in Figure 3, B-D. By contrast, current generated by P532G was inhibited 44\%, and as discussed above, current generated by $\Delta \mathrm{C}$-term ${ }_{527}$ also predicted to lack an $\alpha$-helix was inhibited $51 \%$.

CD spectroscopy. CD spectroscopy was performed on 4 peptides of 29- to 30-amino acid length centered on position 532. As shown in Figure 4, the peptide derived from the wild-type channel showed no evidence of organization, whereas that corresponding to P532L demonstrated a clear structure, compatible with the presence of an $\alpha$-helix. The P532G peptide, predicted to lack an $\alpha$-helix and exhibiting wild-type quinidine sensitivity, also displayed no evidence of organization. By contrast, the

Table 1

Wild-type and P532L KCNA5 in HEK cells

\begin{tabular}{|c|c|c|c|c|c|c|c|}
\hline & $\begin{array}{l}\text { Activating current } \\
\text { at }+50 \mathrm{mV}(\mathrm{pA} / \mathrm{pF})\end{array}$ & $\begin{array}{c}\mathrm{V}_{1 / 2} \text { activation } \\
(\mathrm{mV})\end{array}$ & $\begin{array}{c}\tau_{\text {activation fast at }} \\
+50 \mathrm{mV}(\mathrm{ms})\end{array}$ & $\begin{array}{c}\tau_{\text {activation }} \text { slow at } \\
+\mathbf{5 0 ~ m V ( m s )}\end{array}$ & $\begin{array}{c}\tau_{\text {deactivation }} \text { fast } \\
\text { at }-30 \mathrm{mV}(\mathrm{ms})\end{array}$ & $\begin{array}{c}\tau_{\text {deactivation }} \text { slow } \\
\text { at }-30 \mathrm{mV}(\mathrm{ms})\end{array}$ & $\begin{array}{c}\text { I Kur block by } 10 \mu \mathrm{M} \\
\text { quinidine (\%) }\end{array}$ \\
\hline Wild-type & $402 \pm 41$ & $-6.02 \pm 1.47$ & $1.46 \pm 0.18$ & $7.12 \pm 1.17$ & $13.80 \pm 1.30$ & $57.22 \pm 3.77$ & $50.4 \pm 4.4$ \\
\hline P532L & $396 \pm 39$ & $-6.40 \pm 1.98$ & $1.46 \pm 0.19$ & $6.69 \pm 0.58$ & $5.74 \pm 0.68$ & $49.32 \pm 7.35$ & $8.0 \pm 2.2$ \\
\hline
\end{tabular}

Activating current is steady-state current measured at the end of a depolarizing pulse to $+50 \mathrm{mV}\left(n=4\right.$ each). $\tau_{\text {activation }}$ fast and slow were measured using a depolarizing pulse to $+50 \mathrm{mV}$. $\tau_{\text {deactivation }}$ fast and slow were measured from the tail current obtained at $-30 \mathrm{mV}$, after a depolarizing pulse to $+50 \mathrm{mV}$. $\mathrm{pA} / \mathrm{pF}$, picoAmpere per picoFarad. 

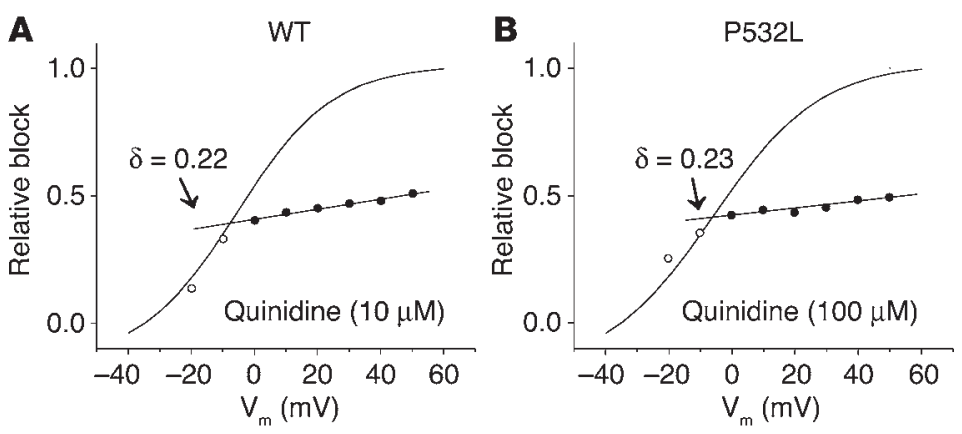

Figure 2

Calculation of $\delta$. (A) Voltage dependence of wild-type KCNA5-mediated current inhibition by quinidine $10 \mu \mathrm{M}$ (near the $\mathrm{IC}_{50}$ ). Current at the end of voltage steps in the presence of drug ( $\left.I_{\text {Drug }}\right)$ was normalized to matching control current ( $\left.I_{\text {Control }}\right)$ and converted to normalized block $\left(1-I_{\text {Drug }} / I_{\text {Control }}\right)$. Below $-20 \mathrm{mV}$, the ratio was undefined (small or no current). The dotted line represents the voltage dependence of $\mathrm{Kv} 1.5$ activation. $\mathrm{V}_{\mathrm{m}}$ indicates membrane voltage; open symbols represent steep voltage dependence of block coinciding with channel activation, and closed symbols, shallow voltage dependence of block. Only the latter data were used in the fit with the Woodhull model (see Methods), shown by the solid line with the indicated values for the equivalent $\delta$. (B) The same experiment as shown in $\mathbf{A}$, with P532L studied at a concentration near the $\mathrm{IC}_{50}(100 \mu \mathrm{M})$.

$\Delta$ P532 peptide, predicted to generate an $\alpha$-helix and resistant to quinidine block, displayed a structure similar to that of P532L.

\section{Discussion}

$\mathrm{P} 532 \mathrm{~L}$ is a human cSNP in the KCNA5 gene that generates a potassium channel nearly indistinguishable from wild type in the absence of drug, but with unexpected resistance to drug block (8). Previous studies have localized the major site of drug binding to the channel at the intracellular face of S6, approximately $20 \%$ inside the electric field from the cytoplasm (9), and suggested that the $\mathrm{C}$ terminus could modulate drug access to a binding site in the mouth of the pore. We report here that P532L exhibits a very similar $\delta$, which suggests that the drug-binding site is the same as that in wild type. Further, we provide strong direct evidence that sensitivity to drug block is tightly linked to the presence or absence of a previously unidentified C-terminal $\alpha$-helix in this region. The presence of a proline, well-recognized as a "helix-breaker," thus facilitates drug block of the wild-type channel.

We envision 2 possible mechanisms for altered drug sensitivity in the variant channel. One is that a conformational change generated by P532L generates, disrupts, or otherwise directly modulates a drug-binding site in the channel. Arguing forcefully against this idea is the near-identical $\delta$ of the wild-type and variant channels, as well as the demonstration that $\Delta \mathrm{C}$-term ${ }_{527}$ generates channels with wild-type drug sensitivity. We therefore hypothesize that the variant does not alter the site on the channel at which drug binds and blocks current, but rather generates a barrier restricting access of drug to this binding site (Figure 5).

A variation on this mechanism would be that generation of an $\alpha$-helix creates a binding site for a second peptide domain that then modulates drug block. This could represent an intramolecular (e.g., $\mathrm{N}$ terminus to $\mathrm{C}$ terminus) or intermolecular (e.g., accessory $\beta$ subunit of voltage-gated $\mathrm{K}^{+}$channel $\left[\mathrm{K}_{\mathrm{v}} \beta\right]$ subunit) interaction. Indeed, the gating of the Kv2.1 channel has been found to be influenced by specific interactions between the $\mathrm{N}$ - and C-terminal domains (15). A 3D structure of the full-length Shaker $\mathrm{K}^{+}$chan- nel $\alpha$-subunit at 25 -Å resolution (16) revealed a larger membrane-embedded domain and a smaller cytoplasmic domain, conjoined by 4 thin connectors resembling a "hanging gondola" (17). The volume of the cytoplasmic domain appeared sufficiently large to accommodate both the $\mathrm{N}$-terminal T1 domain and part of the C-terminal region, which is again compatible with the intramolecular interaction observed in our study; subsequent studies suggested that the $\mathrm{K}_{\mathrm{v}} \beta-2$ subunit interacts with the $\mathrm{C}$ terminus of the Shaker channel (18). $\mathrm{K}_{\mathrm{v}} \beta$ subunits have also been described to modify function of Kv1.5 channels (19), and differences in Kv1.5 amplitude, activation, and deactivation observed when the channel is expressed in different mammalian cell lines have been attributed to variable expression of $\mathrm{K}_{\mathrm{v}} \beta$ subunits (20). In HEK cells, in which $\mathrm{K}_{\mathrm{v}} \beta$ subunit expression is not detected, the mid-point for current activation was $-0.2 \pm 2.0 \mathrm{mV}$ and shifted to $-14.1 \pm 1.8 \mathrm{mV}$ with subunit expression. The present studies were conducted primarily in CHO cells, since HEK cells can display an endogenous potassium current; in $\mathrm{CHO}$ cells, the mid-points for current activation for wild type and P532L were $-5.50 \pm 2.13 \mathrm{mV}$ and $-6.01 \pm 2.81 \mathrm{mV}$, respectively, and values for all other constructs were more positive. The fact that activation and inactivation of mutant channels are very similar to those of wild type, and that the effect is observed in both CHO and HEK cells (Figure 1), argues against a role for altered subunit binding as a primary mechanism for modulating drug block.

Resistance to drug action by the generation of such a barrier is not unexpected but has not previously been described for ion channels. Importantly, whereas previous experiments have used specifically engineered mutants to address the determinants of drug binding, the experiments described here were designed based
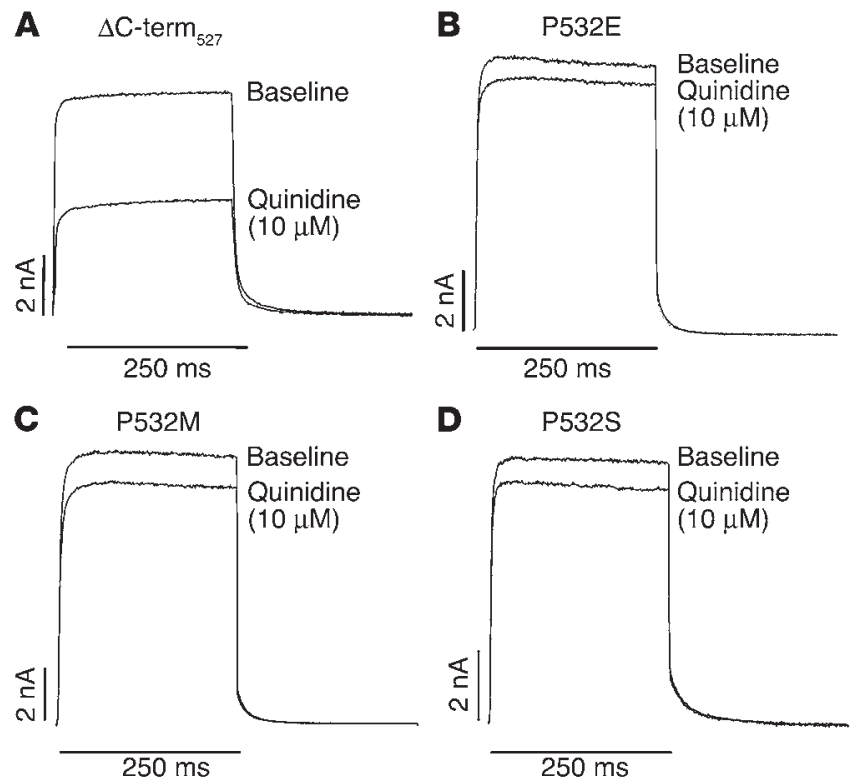

Figure 3

Electrophysiology and drug sensitivity of KCNA5 variants. (A) Current generated by $\Delta \mathrm{C}$-term ${ }_{527}$. The current displays wild-type sensitivity to drug. (B-D) P532E, P532M, and P532S, displaying resistance to drug block. 


\section{Table 2}

Mutant KCNA5 in $\mathrm{CHO}$ cells

\begin{tabular}{|c|c|c|c|c|c|c|c|}
\hline & $\begin{array}{l}\text { Activating current } \\
\text { at }+50 \mathrm{mV}(\mathrm{pA} / \mathrm{pF})\end{array}$ & $\begin{array}{l}\mathrm{V}_{1 / 2} \text { activation } \\
(\mathrm{mV})\end{array}$ & $\begin{array}{c}\tau_{\text {activation }} \text { fast at } \\
+50 \mathrm{mV}(\mathrm{ms})\end{array}$ & $\begin{array}{l}\tau_{\text {activation }} \text { slow at } \\
+50 \mathrm{mV}(\mathrm{ms})\end{array}$ & $\begin{array}{c}\tau_{\text {deactivation }} \text { fast } \\
\text { at }-30 \mathrm{mV}(\mathrm{ms})\end{array}$ & $\begin{array}{c}\tau_{\text {deactivation }} \text { slow } \\
\text { at }-30 \mathrm{mV}(\mathrm{ms})\end{array}$ & $\begin{array}{c}\text { IKur block by } 10 \mu \mathrm{M} \\
\text { quinidine (\%) }\end{array}$ \\
\hline \multicolumn{8}{|c|}{ Constructs predicted to lack an $\alpha$-helix } \\
\hline $\begin{array}{l}\mathrm{P} 532 \mathrm{G} \\
\Delta \mathrm{C} \text {-term }\end{array}$ & $\begin{array}{l}403 \pm 36 \\
398 \pm 57\end{array}$ & $\begin{array}{r}-1.01 \pm 1.45 \\
4.28 \pm 2.13^{B}\end{array}$ & $\begin{array}{l}1.25 \pm 0.18 \\
1.25 \pm 0.38\end{array}$ & $\begin{array}{l}6.21 \pm 1.70 \\
6.72 \pm 0.52\end{array}$ & $\begin{array}{l}9.56 \pm 2.76^{A} \\
4.75 \pm 0.94^{B}\end{array}$ & $\begin{array}{l}45.18 \pm 5.52^{A} \\
35.34 \pm 8.14^{A}\end{array}$ & $\begin{array}{l}43.9 \pm 6.2 \\
51.3 \pm 2.5\end{array}$ \\
\hline \multicolumn{8}{|c|}{ Constructs predicted to generate an $\alpha$-helix } \\
\hline $\begin{array}{l}\triangle P 532 \\
\text { P532A } \\
\text { P532E } \\
\text { P532M } \\
\text { P532S }\end{array}$ & $\begin{array}{l}404 \pm 25 \\
397 \pm 46 \\
394 \pm 29 \\
408 \pm 43 \\
387 \pm 28\end{array}$ & $\begin{array}{c}-0.53 \pm 1.64 \\
-2.60 \pm 2.96 \\
-3.34 \pm 1.81 \\
14.49 \pm 0.68^{\mathrm{B}} \\
3.69 \pm 3.56\end{array}$ & $\begin{array}{l}1.31 \pm 0.22 \\
1.35 \pm 0.37 \\
1.30 \pm 0.15 \\
1.28 \pm 0.14 \\
1.32 \pm 0.11\end{array}$ & $\begin{array}{l}5.70 \pm 1.28 \\
5.05 \pm 1.73 \\
6.93 \pm 1.03 \\
7.64 \pm 0.28 \\
7.05 \pm 0.23\end{array}$ & $\begin{array}{r}4.31 \pm 0.99 \mathrm{~B} \\
3.79 \pm 1.30^{\mathrm{B}} \\
13.07 \pm 1.67 \\
13.90 \pm 1.76 \\
13.17 \pm 0.69\end{array}$ & $\begin{array}{l}33.96 \pm 7.50^{A} \\
32.64 \pm 4.32^{A} \\
55.57 \pm 7.37 \\
55.06 \pm 3.90 \\
62.01 \pm 2.38\end{array}$ & $\begin{array}{r}10.7 \pm 3.9^{B} \\
9.9 \pm 2.3^{B} \\
6.9 \pm 2.9^{B} \\
11.3 \pm 2.0^{B} \\
10.2 \pm 2.2^{B}\end{array}$ \\
\hline
\end{tabular}

( pulse to $+50 \mathrm{mV}$. $\tau_{\text {activation }}$ fast and slow were measured using a depolarizing pulse to $+50 \mathrm{mV}$. $\tau_{\text {deactivation }}$ fast and slow were measured from the tail current obtained at $-30 \mathrm{mV}$, after a depolarizing pulse to $+50 \mathrm{mV}$.

on findings with a naturally occurring, albeit uncommon, human DNA polymorphism. In these experiments we used quinidine, but we have previously demonstrated that P532L channels also exhibit striking resistance to block by propafenone (8). In addition, we have reported that PKA-dependent phosphorylation in the $\mathrm{N}$ and $\mathrm{C}$ termini of KCNQ1, another voltage-gated $\mathrm{K}^{+}$channel, inhibits drug block and suggested that the access of blocking drugs to a binding site in the pore was impaired in the phosphorylated channel (21). Thus, the concept of an intracytoplasmic access pathway to a pore binding site for drugs may have some generalizability.

Other ion channel variants appear to alter sensitivity to drug block and have in fact been linked to the development of drug-induced arrhythmias in patients (22-24). However, unlike P532L, these variants produce readily detectable changes in channel function in vitro in the absence of drug. Clinical studies in large patient populations will be required to test the hypothesis that patients with atrial fibrillation and the P532L variant will be resistant to drugs whose mechanism of antiarrhythmic action in this setting includes $\mathrm{I}_{\text {Kur }}$ block.

\section{Methods}

Construction and expression of recombinant KCNA5 channels. Variants of KCNA5 were engineered into the PBK-CMV Phagemid Vector (Stratagene) using the QuikChange Site-Directed Mutagenesis Kit (Stratagene). The identity of the inserts was verified by sequencing. Vectors expressing wild-type or mutant KCNA5 were transfected into CHO or HEK cells for subsequent electrophysiological study; $2 \mu \mathrm{g}$ of KCNA5 cDNA and $6 \mu$ of the FuGENE 6 Transfection Reagent (Roche Diagnostics Corp.) were used. GFP was coexpressed to identify transfected cells.

Electrophysiological studies. Kv1.5 currents were measured using the wholecell configuration of the patch-clamp technique in cells maintained at room temperature $\left(22-23^{\circ} \mathrm{C}\right)$, unless otherwise indicated. Cells were held at $-80 \mathrm{mV}$ and pulsed to -30 to $+50 \mathrm{mV}$ for $250 \mathrm{~ms}$, and tail currents were then measured at $-30 \mathrm{mV}$. The composition of superfusion and internal pipette solutions were described previously $(8,25)$.

A first-order blocking scheme was used to describe the drug-channel interaction $(9,13)$. The apparent affinity $\left(K_{\mathrm{D}}\right.$, representing the $\left.\mathrm{IC}_{50}\right)$ and Hill coefficient $(n)$ were obtained by fitting the fractional block $(f)$ at various drug concentrations $([D])$ to the equation $f=1 /\left(1+\left(K_{\mathrm{D}} /[D]\right)^{n}\right)$. The electrical binding distance, $\delta$, i.e., the fraction of the transmembrane field sensed by a single charge at the receptor site, was calculated from the
Woodhull equation (26): $f=[D] /\left([D]+K_{\mathrm{D}} * \times \mathrm{e}^{-\delta z F E / R T}\right)$, where $z$ is the valence $(+1$ for cationic quinidine), $F$ the Faraday constant, $E$ the transmembrane electrical potential, $R$ the gas constant, and $T$ the absolute temperature. $K_{\mathrm{D}} *$ represents the apparent affinity at the reference voltage $(0 \mathrm{mV})$.

Secondary structure prediction. The sequence-based prediction algorithm Network Protein Sequence Analysis (http://npsa-pbil.ibcp.fr/cgi-bin/ npsa_automat.pl?page=/NPSA/npsa_server.html) (27) was used to identify possible structural motifs near position 532 in the $\mathrm{C}$ terminus of the KCNA5 protein. Peptides corresponding to wild-type (NFNYFYHRETDHEEPAVLKEEQGTQSQGPG) and sequence variants (L, $G$, or $P$ at position 532 deleted without substitution) were custom synthesized to $95 \%$ purity by BioSource International.

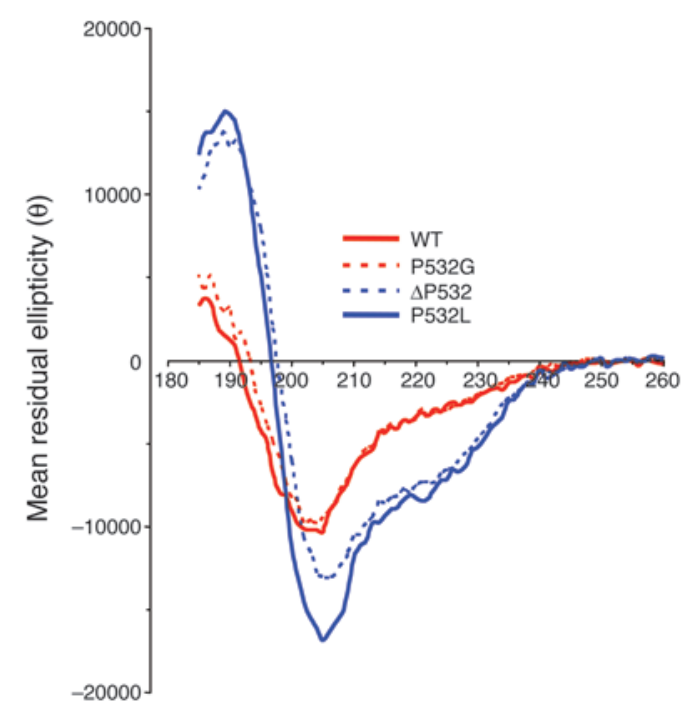

\section{Figure 4}

CD spectra from 185 to $260 \mathrm{~nm}$ in 2,2,2-trifluoroethanol, 40\% vol/vol, at $25^{\circ} \mathrm{C}$. The red traces represent data obtained using peptides lacking structural organization (solid line, wild type; dashed line, P532G). The blue traces were derived using peptides predicted to generate $\alpha$-helices (solid line, P532L; dashed line, $\triangle$ P532, in which the proline at position 532 is deleted without substitution). The blue traces display minima at 208 and $222 \mathrm{~nm}$, typical of $\alpha$-helices. 
WT

P532L

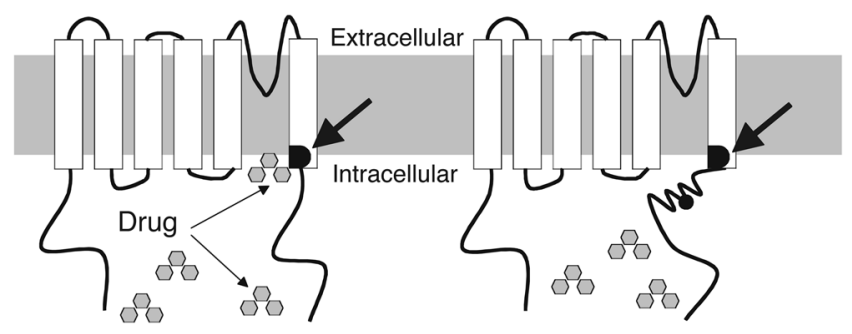

Figure 5

Schematic representation of KCNA5 with its intracellular S6 drug binding site, indicated by arrows. The right panel illustrates the concept that generation of a C-terminal $\alpha$-helical secondary structure in the P532L variant (black dot) would restrict access of the drug to the $\mathrm{S} 6$ binding site.

CD spectroscopy. CD spectra were acquired on a Jasco J-810 spectropolarimeter equipped with a Peltier-controlled temperature block using a 1-mm path length quartz cuvette. The data were collected at $1-\mathrm{nm}$ increments from 185 to $260 \mathrm{~nm}$ using a response time of 2 seconds and a scan speed of $10 \mathrm{~nm} / \mathrm{min}$. Spectra represent an average of 2 scans with the background corrected against a buffer blank. Data are reported as mean residue ellipticity, $[\theta]\left(\mathrm{deg} \times \mathrm{cm}^{2} \times \mathrm{dmol}^{-1}\right)$, which was calculated as $[\theta]=100 \times($ signal $) /(C \times n \times l)$, where deg represents degrees; signal represents raw output in mdeg; $C$ represents peptide concentration in millimolar; $n$ represents number of amino acid residues; and $l$ represents cell path length in centimeters.

Stock peptide solutions were prepared by dissolving lyophilized powder in water. Concentrations of stock solutions were determined by measuring the tyrosine absorbance at $280 \mathrm{~nm}$ assuming an extinction coefficient of $2,560 \mathrm{M}^{-1} \mathrm{~cm}^{-1}$ (28). Samples for $\mathrm{CD}$ were prepared by dilution of the peptide stocks and contained $10 \mathrm{mM}$ potassium phosphate, $\mathrm{pH} 7.5$, and $40 \%$ (vol/vol) 2,2,2-trifluoroethanol.

Statistical analysis. Time constants for $\mathrm{I}_{\text {Kur }}$ activation $\left(\tau_{\text {activation }}\right.$ fast and $\tau_{\text {activation }}$ slow) were determined by fitting activating current during a pulse to $+50 \mathrm{mV}$ to a biexponential function, and time constants for deactivation ( $\tau_{\text {deactivation }}$ fast and $\tau_{\text {deactivation }}$ slow) were similarly determined from the tail current at $-30 \mathrm{mV}$ after a pulse to $+50 \mathrm{mV}$. The voltage at which channels were $50 \%$ activated $\left(\mathrm{V}_{1 / 2}\right)$ was obtained by fitting the Boltzmann function to current-voltage $(I-V)$ relations: $I=I_{\max } /\left(1+\exp \left[\left(V-V_{1 / 2}\right) / k\right]\right)$, where $I_{\max }$ is the maximal current and $k$ represents the slope factor. Data are presented as mean \pm SEM. Differences between wild-type and mutant currents were analyzed with 1 -way ANOVA. A $P$ value $<0.05$ was considered statistically significant.

\section{Acknowledgments}

The authors thank Donna Choate for her helpful assistance. This work was supported in part by the Vanderbilt Center for Structural Biology and a grant from the United States Public Health Service (U01 HL65962). D.M. Roden holds the William Stokes Chair in Experimental Therapeutics, a gift from the Dai-ichi Corp. Benoit Drolet was the recipient of a postdoctoral fellowship award from the Canadian Institutes of Health Research and the Heart and Stroke Foundation of Canada.

Received for publication November 26, 2004, and accepted in revised form May 24, 2005.

Address correspondence to: Dan M. Roden, Division of Clinical Pharmacology, Vanderbilt University School of Medicine, 532 Medical Research Building I, Nashville, Tennessee 37232, USA. Phone: (615) 322-0067; Fax: (615) 343-4522; E-mail: dan.roden@ vanderbilt.edu.
1. Tamkun, M.M., et al. 1991. Molecular cloning and characterization of two voltage-gated $\mathrm{K}^{+}$ channel cDNAs from human ventricle. FASEBJ. 5:331-337.

2. Snyders, D.J., Tamkun, M.M., and Bennett, P.B. 1993. A rapidly-activating and slowly-inactivating potassium channel cloned from human heart. J. Gen. Physiol. 101:513-543.

3. Fedida, D., et al. 1993. Identity of a novel delayed rectifier current from human heart with a cloned $\mathrm{K}^{+}$channel current. Circ. Res. 73:210-216.

4. Nattel, S. 2002. New ideas about atrial fibrillation 50 years on [review]. Nature. 415:219-226.

5. Roden, D.M. 2001. Pharmacogenetics and druginduced arrhythmias. Cardiovasc. Res. 50:224-231.

6. Roden, D.M. 2003. Antiarrhythmic drugs: past, present and future [review]. J. Cardiovasc. Electrophysiol. 14:1389-1396.

7. Dorian, P. 2003. Antiarrhythmic drug therapy of atrial fibrillation: focus on new agents [review]. J. Cardiovasc. Pharmacol. Ther. 8(Suppl. 1):S27-S31.

8. Simard, C., Drolet, B., Yang, P., Kim, R.B., and Roden, D.M. 2005. Polymorphism screening in the cardiac $\mathrm{K}+$ channel gene KCNA5. Clin. Pharmacol. Ther. 77:138-144.

9. Yeola, S.W., Rich, T.C., Uebele, V.N., Tamkun, M.M., and Snyders, D.J. 1996. Molecular analysis of a binding site for quinidine in a human cardiac delayed rectifier $\mathrm{K}^{+}$channel - role of $\mathrm{S} 6$ in antiarrhythmic drug binding. Circ. Res. 78:1105-1114.

10. Ragsdale, D.S., McPhee, J.C., Scheuer, T., and Catterall, W.A. 1994. Molecular determinants of statedependent block of $\mathrm{Na}^{+}$channels by local anesthetics. Science. 265:1724-1728.
11. Striessnig, J., Murphy, B.J., and Catterall, W.A. 1991. Dihydropyridine receptor of L-type Ca2+ channels: identification of binding domains for $[3 \mathrm{H}](+)-\mathrm{PN} 200-110$ and $[3 \mathrm{H}]$ azidopine within the alpha 1 subunit. Proc. Natl. Acad. Sci. U. S. A. 88:10769-10773.

12. Mitcheson, J.S., Chen, J., Lin, M., Culberson, C. and Sanguinetti, M.C. 2000. A structural basis for drug-induced long QT syndrome. Proc. Natl. Acad. Sci. U. S. A. 97:12329-12333.

13. Snyders, D.J., and Yeola, S.W. 1995. Determinants of antiarrhythmic drug action electrostatic and hydrophobic components of block of the human cardiac hKv1.5 channel. Circ. Res. 77:575-583.

14. Fedida, D. 1997. Gating charge and ionic currents associated with quinidine block of human Kv1.5 delayed rectifier channels. J. Physiol. 499:661-675.

15. Ju, M., Stevens, L., Leadbitter, E., and Wray, D. 2003. The roles of $\mathrm{N}$ - and $\mathrm{C}$-terminal determinants in the activation of the Kv2.1 potassium channel. J. Biol. Chem. 278:12769-12778.

16. Sokolova, O., Kolmakova-Partensky, L., and Grigorieff, N. 2001. Three-dimensional structure of a voltage-gated potassium channel at $2.5 \mathrm{~nm}$ resolution. Structure (Camb.). 9:215-220.

17. Kobertz, W.R., Williams, C., and Miller, C. 2000 Hanging gondola structure of the T1 domain in a voltage-gated $\mathrm{K}(+)$ channel. Biochemistry. 39:10347-10352.

18. Sokolova, O., et al. 2003. Conformational changes in the $\mathrm{C}$ terminus of Shaker $\mathrm{K}+$ channel bound to the rat Kvbeta2-subunit. Proc. Natl. Acad. Sci. U. S. A. 100:12607-12612.

19. England, S.K., et al. 1995. Characterization of a voltage-gated $\mathrm{K}^{+}$channel beta subunit expressed in human heart. Proc. Natl. Acad. Sci. U. S. A. 92:6309-6313.

20. Uebele, V.N., England, S.K., Chaudhary, A., Tamkun, M.M., and Snyders, D.J. 1996. Functional differences in Kv1.5 currents expressed in mammalian cell lines are due to the presence of endogenous $\mathrm{Kv}$ beta 2.1 subunits. J. Biol. Chem. 271:2406-2412.

21. Yang, T., Kanki, H., and Roden, D.M. 2003. Phosphorylation of the IKs channel complex inhibits drug block. Novel mechanism underlying variable antiarrhythmic drug actions. Circulation. 108:132-134.

22. Sesti, F., et al. 2000. A common polymorphism associated with antibiotic-induced cardiac arrhythmia. Proc. Natl. Acad. Sci. U. S. A. 97:10613-10618.

23. Yang, P., et al. 2002. Allelic variants in Long QT disease genes in patients with drug-associated torsades de pointes. Circulation. 105:1943-1948.

24. Splawski, I., et al. 2002. Variant of SCN5A sodium channel implicated in risk of cardiac arrhythmia. Science. 297:1333-1336.

25. Yang, T., Snyders, D., and Roden, D.M. 2001. Drug block of $\mathrm{I}(\mathrm{kr})$ : model systems and relevance to human arrhythmias. J. Cardiovasc. Pharmacol. 38:737-744.

26. Woodhull, A.M. 1973. Ionic blockage of sodium channels in nerve. J. Gen. Physiol. 61:687-708.

27. Combet, C., Blanchet, C., Geourjon, C., and Deleage, G.2000. NPS@: network protein sequence analysis [review]. Trends Biochem. Sci. 25:147-150.

28. Gill, S.C., and von Hippel, P.H. 1989. Calculation of protein extinction coefficients from amino acid sequence data. Anal. Biochem. 182:319-326. 